\title{
Influência e contrainfluência na inversão do poder tipográfico entre Portugal e o Brasil. Narrativa e atividade nos editores portugueses
}

\section{Influence and counter-influence in the inversion of the publishing power between Portugal and Brazil. Narrative and activity of Portuguese publishers}

Nuno Miguel Ribeiro de MEDEIROS*

Resumo: Tempo fértil em alterações que transformaram a face do universo editorial em Portugal e no Brasil, os anos que decorrem entre a última metade da década de 1930 e o fim da década de 1960 constituem o período em que se assiste a uma inversão nos processos de influência tipográfica entre os dois países, com Portugal a passar de exportador para importador de livros no seu comércio com o Brasil. Este artigo pretende analisar o ponto de vista da edição portuguesa nos modos variados como os seus agentes foram representando o Brasil enquanto centro produtor e disseminador do livro, e como as mudanças suscitadas foram ocorrendo num contexto de oscilação - e tensão - entre discursos amarrados a uma época de ouro (ou imaginada como tal) que ficava relutantemente para trás e práticas de colaboração efectiva entre os universos tipográficos português e brasileiro, essencialmente suportadas na actuação de editores individuais.

Palavras-chave: Mercado do livro. Portugal. Brasil. Influência tipográfica.

\begin{abstract}
There was a time of many alterations that changed the face of the publishing world in Portugal and Brazil during the years spanning from the second half of the 1930's to the end of the 1960's. This was a period in which one could observe an inversion of publishing influences between the two countries, with Portugal shifting its role and becoming a net book importer in its trade with Brazil. This article intends to analyze the Portuguese publishing world's point of view as their agents in different ways changed their attitudes toward Brazil as a centre of book production and diffusion. The text also sets out to understand how these transformations occurred in a context

\footnotetext{
* Mestre em Sociologia Histórica. Doutorando em Sociologia Histórica da Cultura (Universidade Nova de Lisboa). Professor de Sociologia - Departamento das Ciências Sociais e Humanas - Escola Superior de Tecnologia da Saúde de Lisboa - IPL - Instituto Politécnico de Lisboa - Av. D. João II, Lote 4.69.01, 1990-096 Lisboa, Portugal. Pesquisador de Sociologia Histórica - CesNova, Centro de Estudos de Sociologia da Universidade Nova de Lisboa - Faculdade de Ciências Sociais e Humanas - UNL - Universidade Nova de Lisboa - Av. de Berna, 26-C, 1069-061, Lisboa, Portugal. E-mail: nuno.medeiros@fcsh.unl.pt
} 
of oscillation - and tension - among discourses tied to a golden age (or imagined as such) that was reluctantly left behind, and practices of effective collaboration between the Portuguese and Brazilian publishing worlds - resulting fundamentally from the actions of individual publishers.

Keywords: Book market. Portugal. Brazil. Publishing influence.

\section{O Brasil como mercado receptor do livro português e o princípio do direito histórico à} subordinação

Nas relações estabelecidas entre Portugal e Brasil, tendo como pano de fundo o livro e o mercado editorial, é possível descortinar um conjunto de circunstâncias e um tempo que as enquadra, em que as alterações nas respectivas estruturas editoriais e livreiras, com maior incidência talvez no caso brasileiro, transformam os universos do livro editado nos dois países. Situado essencialmente nos cerca de trinta anos que decorrem entre a segunda metade dos anos 1930 e finais da década de 1960, esse tempo parece constituir o ciclo completo em que se consuma o que noutro local se designou de inversão nos processos de influência tipográfica entre os dois países (MEDEIROS, 2010), troca que se traduziu genericamente no fato de Portugal passar de exportador líquido para importador líquido nas suas transações com o Brasil no atinente ao livro, traduzindo-se ainda no crescimento das referências brasileiras - fundamentalmente, mas não exclusivamente, literárias - no espaço editorial português.

Nesta inversão, jogam-se tanto as alterações das posições ocupadas pelos dois países no quadro do comércio livreiro e editorial constitutivo de um mercado do livro lusófono de escala internacional (escala mais projetada e desejada do que real), quanto às correlativas posições simbólicas no contexto das primazias históricas no plano da influência cultural e literária. O processo põe a nu elementos estruturais que suportam os métodos de produção e comercialização do livro, para além das componentes ideológicas por meio das quais essa produção e comercialização são interpretadas. As representações assim engendradas, capazes de se reproduzir no tempo, adquirem um sentido que, no caso em análise, se funda numa relação entre dois sistemas-livro, para retomar a feliz expressão de Frédéric Barbier (2001), historicamente vista e sentida de modo assimétrico. As dinâmicas de mudança exercem efeitos perturbadores da ordem mercantil e representacional instaurada, originando respostas e contrarrespostas cuja lógica pode ser entrevista no jogo tensional de estratégias de influência e de contrainfluência postas em campo por cada um dos sistemas-livro, cada um procurando fazer valer num conjunto de planos - produtivo, econômico, cultural, político e até diplomático - as legitimidades antigas ou as recém-conquistadas. 
Influência e contra-influência na inversão do poder tipográfico entre Portugal e o Brasil. Narrativa e actividade nos editores portugueses

Tal parece ser, até certo ponto, o caso do Brasil e de Portugal no que respeita ao livro. O modelo assim traçado sofre, contudo, o desafio da ação de determinados tipos de agente, sobretudo individuais (editores e livreiros), que procura concretizar o estabelecimento ou a atualização de vínculos colaborativos por meio da venda e edição de livros de autores e temas brasileiros em Portugal e vice-versa. Nota-se que na realidade estudada, o editor apresentado como exemplo sustentou a sua intervenção numa matriz de aproximação cultural entre dois mundos, embora a sua atuação não se encontrasse desamarrada de uma orientação mercantil.

As relações entre os setores editoriais dos dois países seguiram um trajeto repleto, tanto de escolhos como de vias de aproximação, com avanços e retrocessos. Do ponto de vista das práticas discursivas e das representações de um número significativo de editores portugueses, durante muito tempo o universo brasileiro do livro e da leitura é onipresente na retórica sobre o desenvolvimento do livro português e do seu mercado, bem como no posicionamento editorial português acerca do intercâmbio cultural lusófono, missão cuja direção e promoção, aliás, muitos agentes do livro portugueses creem ser pertença natural de Portugal. Até aos anos 60 do século XX, o discurso preponderante construído pelas gentes do livro portuguesas - nomeadamente, mas não exclusivamente, pelos editores - face ao mercado brasileiro ainda se apega à antiga ideia de dependência deste como subproduto de colonização cultural. Com efeito, o resíduo de um mercado mitificado como o brasileiro é ainda sensível nos modos de pensar a própria atividade de editar. Fortemente habituados à situação histórica de relativa dependência e incipiência do mercado do livro no Brasil, os editores portugueses tendem a observar-se como centro a quem está reservado um papel de alimentação de um público e de um sistema livreiro que lhe são fiéis.

O princípio do direito histórico à influência cultural sobre o território brasileiro, não assumido mas patente na matriz discursiva dos editores portugueses, suportava-se na perpetuação de uma visão do espaço brasileiro do livro a partir de uma lente que reduzia este espaço a um mercado-recipiente, condição parcialmente tributária de debilidades que até certa altura o Brasil manifestou em termos de crescimento e maturidade livreiras e, sobretudo, editoriais. Esta condição tinha, decerto, raízes históricas de todos conhecidas, sendo simbolicamente representada pela instalação, no Rio de Janeiro, da Impressão Régia, em 1808, o marco inicial da atividade permanente de tipografia em terras brasileiras, consideravelmente tardio em relação a casos análogos noutras colônias do continente americano (ABREU, 2010); instalação tardia, refira-se, não apenas motivada por uma vontade exclusiva dos editores e livreiros metropolitanos e pela sua capacidade de influência política (BRAGANÇA, 2005, 2010). Mas esta mesma condição, e a eternização de sua percepção no lado português, a partir de determinado momento 
convenientemente míope face ao inegável surto de desenvolvimento e autonomização do setor livreiro e editorial brasileiro (BRAGANÇA; ABREU, 2010), revelaram-se efetivamente incompatíveis com esse mesmo dado crescentemente indesmentível: o de que a realidade se havia transmutado. E mudara tanto, que se pode considerar que, ao longo terço de século localizado entre meados da década de 1930 e finais da década de 1960, as relações de influência no que se refere ao livro se invertem.

Impõe-se, neste momento, um ponto de ordem teórico, balizador do esforço analítico de que se procura dar breve conta no presente artigo. O termo poder, referido no título, não remete para uma conceitualização que o encare como produto inerte de uma assimetria forjada numa visão de dominação entre partes detentoras de recursos desproporcionais. O enfoque que aqui se adota centra-se mais numa concepção de relação entre sistemas-livro fundados em redes complexas de ligação, com produção e circulação de ideias e objetos (impressos) localizadas em diversas frentes nacionais, mesmo nas que usualmente são estudadas como dominadas. Perscrutar Portugal e Brasil como unidades particulares de estudo não é, nesse sentido, equivalente a observar os universos do livro destes dois países como dados nacionais naturalizados e, portanto, como objetos de estudo desconectados de unidades mais vastas, eventualmente o próprio mundo. Na verdade, e como bem notam Roger Chartier (1996, 1997, 2001) e Márcia Abreu (2011), a explicação da realidade do livro deve contemplar, na sua forma de conhecimento, as ideias de abertura, imbricação e apropriação, quer se trate, entre outros exemplos possíveis, de compreender a leitura enquanto diferença social entre as intenções do editor que edita um livro e os desvios a essas intenções efetuados pelo leitor (CERTEAU, 1990; MEDEIROS, 2006), quer se trate de esclarecer as múltiplas ligações tipográficas e literárias entre países.

Sendo certo que o entorno em que emergem as formas de circulação da cultura impressa se caracteriza pela multipolaridade e por manifestações e circuitos de capilaridade e infidelidade, ${ }^{1}$ essas formas de circulação ocorrem, porém, num cenário variado e desigual, moldado por modos e temporalidades específicas na constituição da cultura impressa em cada país ou região. Desse ponto de vista, empreender diligências analíticas que possam aclarar o diferencial de influência - logo, de poder - entre os universos do livro de espaços nacionais ou plurinacionais diversos, significa a exploração não-linear do objeto também com base em categorias explicativas como autonomia ou dependência. Tais categorias, essenciais à proposta que aqui se apresenta, reportam-se tanto a circunstâncias objetivas de mercado quanto a modos subjetivos de concebê-lo. Se é verdade que, ao longo de todo o século XIX, se intensifica a circulação de livros e de toda a sorte de objetos impressos fabricados num dos dois países e exportado para o outro, tendo até mesmo os editores portugueses sentido a concorrência do comércio de livros impressos no Brasil, não o é menos o fato 
Influência e contra-influência na inversão do poder tipográfico entre Portugal e o Brasil. Narrativa e actividade nos editores portugueses

de que “a pujança do mundo editorial lusitano” (ABREU, 2011, p. 123) correspondia a um setor com uma sedimentação incomparável ao homólogo brasileiro. Daí poder falar-se em inversão do poder tipográfico, apesar da miríade de pequenas inversões registrada durante oitocentos, porque ela representa - de certa forma e a partir de dado momento, de modo indelével no discurso dos editores portugueses - uma viragem mais clara e duradoura na estrutura das relações entre os dois sistemaslivro.

\section{Dinâmicas de influência e contrainfluência no livro: sentimentos e estratégias}

Para a perda de influência sentida pelos agentes do livro portugueses concorreu, antes de mais, um conjunto de fatores endógenos, como a censura e a repressão intelectual e social, a ausência de políticas públicas para o livro, a tenacidade de elevados índices de analfabetismo, ou mesmo a persistência de práticas de timbre artesanal das próprias gentes do livro (MEDEIROS, 2010). Mas, para além da interferência persecutória do Estado Novo no setor do objeto impresso e dos traços inerentes aos modos como, sobretudo os editores, exerciam a sua atividade, reconheça-se que os atores do setor vão se encontrar ainda limitados por um contexto adverso no que concerne à dimensão externa, nomeadamente nas relações com o universo tipográfico brasileiro. Avultam como exemplos neste caso, e para quem quisesse exportar livros com regularidade para o outro lado do Atlântico, as diferenças cambiais e o peso dos portes para o Brasil, a desvalorização do cruzeiro - e consequentes inflação do preço final dos volumes importados e congelamento pelo Banco do Brasil do pagamento das dívidas aos exportadores de livros portugueses - ou os desacordos entre mercados no que se refere à aquisição de direitos para a língua portuguesa. De passagem, cita-se a questão das importações de livros editados em Portugal que recobria outro aspecto, susceptível, como foi, de acirrar divergências e suscitar aproveitamentos: a ausência de unificação ortográfica da língua (ANÓNIMO, 1955).

Aos obstáculos puramente comerciais à exportação de livros para o Brasil com que os editores portugueses passaram a confrontar, acrescenta-se uma oposição de base legal, decretada pelos poderes públicos brasileiros, corporizada pela legislação proibicionista de traduções portuguesas e originais brasileiros publicados em Portugal. A opção pela interdição, ordenada compulsoriamente, exemplifica o timbre estratégico de uma ação de contrainfluência, na qual podem concertar diversos atores, como o próprio Estado. Habituados, desde sempre, a escoar para o mercado brasileiro parte do que produziam, os editores portugueses - ou pelo menos um conjunto não desprezível deles - passou a enfrentar, já no fim dos anos 1940, um escolho que se veio a revelar de muito difícil superação. A circunstância encontra-se, juridicamente, em 3 de setembro de 
1948, data de promulgação pelo governo brasileiro do Decreto n. ${ }^{\circ} 25.442$, posteriormente alterado pelas Leis n. ${ }^{\circ}$ 842, de 4 de outubro de 1949, e n. ${ }^{\circ}$ 2.145, de 19 de dezembro de 1953. Com este diploma, o Brasil lograva impedir a importação de obras de autores estrangeiros, traduzidos ou editados em Portugal. No primeiro Congresso de Editores e Livreiros do Brasil, acontecido justamente em 1948 e promovido pela Câmara Brasileira do Livro, a situação é objeto de "amplos e vivos debates”, aprovando-se a “recomendação de revogação do Decreto n. ${ }^{0}$ 25.442”, com 32 votos a favor, 4 contra e 2 abstenções. Aprova-se, ainda, a comunicação imediata da decisão tomada ao Grémio Nacional dos Editores e Livreiros, o organismo português de representação das respectivas classes profissionais (CÂMARA BRASILEIRA DO LIVRO, 1950, p. $44-45$ e 99). Na verdade, a legislação não definia uma proibição pura e simples, mas uma licença prévia, de amplo âmbito excludente, considerada pelos editores portugueses “morosa e difícil” (GRÉMIO NACIONAL DOS EDITORES E LIVREIROS, n. 61, jun. 1952, p. 1-2). Já no segundo congresso, decorrido em novembro de 1954, a corrente de opinião majoritária se expressa em sentido inverso. As resoluções no que concerne à interdição de traduções portuguesas no Brasil foram no sentido da manutenção do statu quo em vigor havia seis anos e que possibilitava essencialmente a importação de livros portugueses de temática religiosa ou, casuisticamente, do domínio público (GRÉMIO NACIONAL DOS EDITORES E LIVREIROS, n. 85, dez. 1954, p. 7-8). No terceiro congresso, realizado em novembro de 1956, apesar da legislação inibitória ter sido já eliminada, reverbera ainda nos participantes um certo sentimento protecionista, com a aprovação de uma tese em que se recomenda a elaboração de um "projeto de lei que proíba a entrada no Brasil de traduções portuguesas de autores de Domínio Público aqui já editadas” (GRÉMIO NACIONAL DOS EDITORES E LIVREIROS, n. 100, nov.-dez. 1956, p. 2).

Desta forma, com suporte legal, vedou-se aos editores portugueses durante oito anos o maior receptáculo das exportações dos livros que editavam, o Brasil, não apresentando as colônias africanas e asiáticas um contingente populacional alfabetizado alternativo que justificasse significativas importações da metrópole. Sobre a propagação do livro editado em Portugal nas colônias, Francisco da Cunha Leão redige a informação n. ${ }^{\circ} 1.175$ da Direção Geral de Ensino, de 20 de dezembro de 1952, na qual sistematiza as razões que, em seu entendimento, contribuem para o peso insignificante dos mercados coloniais no comércio e produção editorial portugueses: restrição e fragilidade de rede comercial e de bibliotecas, deficiência ou ausência do sistema de cobranças postais, demora excessiva nas liquidações e inexistência de informação e divulgação quanto aos títulos que são editados. Assim se balizam algumas das múltiplas dificuldades enfrentadas por um setor que, no início dos anos 1950, “representa pouco mais de um milésimo das exportações para o Ultramar”, “em boa parte só removíveis com o decidido apoio do Estado” (LEÃO, 1953, p. 62). 
Influência e contra-influência na inversão do poder tipográfico entre Portugal e o Brasil. Narrativa e actividade nos editores portugueses

Suplementarmente ao fato de não possuir capacidade de expansão entre comunidades linguísticas luso-falantes, a edição portuguesa não pôde contar com as concentrações de emigrantes, cujos atributos mais marcantes foram a baixa ou inexistente literacia e a decorrente ausência generalizada de consumo do livro. Fora destes espaços, as letras portuguesas publicadas são liminarmente ignoradas. A influência do sistema editorial e literário português, em comparação às realidades axiais dotadas de maior alcance na assunção de um papel de referência literária e de irradiação editorial como França (MOLLIER, 2001), não existe. A sua capacidade de inserção num mercado do livro internacional, por meio da venda de exemplares em português ou traduzidos, é quase nula, fator que acentua as consequências econômicas e representacionais do declínio do papel do Brasil como mercado importador da edição portuguesa.

Neste sentido, não parece ser muito arriscada a proposição de que a hermenêutica da relação editorial entre Portugal e Brasil ao longo do século XX não pode abdicar, em boa medida e com maior incidência no período em análise, de ser também a hermenêutica do deslocamento dos termos de subordinação entre dois países. Subordinação em que uma das dimensões principais é constituída pelos discursos e formas de estruturação da atividade face ao outro - o outro enquanto ideia de mercado e enquanto possibilidade concreta de mercado. No que diz respeito à forma de ver o outro no lado português, a visão dominante que parece ter perdurado - e as práticas que a acompanharam - não está certamente desligada do lento e territorialmente desigual desenvolvimento de uma indústria editorial brasileira, tardio face à realidade de outros países sulamericanos. A indústria editorial do Brasil emerge com verdadeira autonomia, apenas a partir dos anos 1920 (HALLEWELL, 1985; DEAECTO, 2011). Paralelo ao aparecimento de uma literatura brasileira assumida como nacional (SORÁ, 1999; MOREIRA, 2010), e nele participando ativamente, o campo autônomo da edição no Brasil cresce com pujança e celeridade, atingindo, na década de 1930, uma dimensão competitiva no plano da produção em língua portuguesa, fato crescentemente assumido pelos próprios membros do universo do livro brasileiro. ${ }^{2}$ É à luz deste processo transformador que se deve compreender a proibição de 1948, que não surge como caso isolado ou extemporâneo, antes sinalizando e ilustrando a materialização de um conjunto de mecanismos de contrainfluência editorial cujo sentido mais global se opera e se observa na escala de mudança social e de mercado que se verificava no Brasil. Em finais da década de 1940 está aberto o caminho para uma inequívoca alteração da relação de dependência do sistema-livro brasileiro com a antiga metrópole (LOPES, 2001), alteração aqui assumida como inversão (num quadro mais vasto de uma dinâmica de movimentos de inversão e contrainversão que pautou a história das relações tipográficas entre os dois países) e que se traduziu num processo de mudança 
para o qual terão concorrido vários agentes e instituições (poderes públicos, poderes de classe, poderes econômicos), cruzando a sua ação numa pluralidade de circunstâncias cujo pano de fundo é a expansão do setor do livro no Brasil.

Sublinhe-se que este processo de inversão do poder tipográfico só será parcialmente revertido - ou mitigado - nos anos 1950 com o incremento da exportação de livros de editores portugueses para o Brasil, aproveitando quer a abolição em 1956 da legislação que interditava na prática a exportação das traduções publicadas em Portugal (GRÉMIO NACIONAL DOS EDITORES E LIVREIROS, n. 97, mai-jun. 1956, p. 1-2), quer a vaga de instabilidade econômica que assolou terras brasileiras, que terá dificultado a produção da indústria local do livro no seu conjunto. A situação financeira do Brasil acabou, contudo, por se revelar uma faca de dois gumes, já que originou perdas sucessivas aos editores portugueses, que iam colecionando dívidas com a volubilidade cambial e o congelamento dos pagamentos de livros importados ordenado no decênio de 1950 pelo Banco Central brasileiro, dando origem à acumulação de créditos em virtude dos anos de espera pela liquidação dos designados “atrasados”, saldados a conta-gotas.

No decurso da década de 1940, face ao contexto em transfiguração na conexão do livro entre os dois países (ou mercados, ou indústrias), a preocupação com a perda do maior e mais seguro mercado para o livro publicado em Portugal crescia no seio dos editores portugueses. Em 11 de fevereiro de 1941, o Diário de Notícias, o jornal diário português de maior circulação, havia lançado, logo na primeira página, “O S.O.S. do livro português”, exortação dramática motivada pelo seu declínio em terras brasileiras. António Teixeira, da Clássica Editora, dá o mote. Para o editor e à época presidente da assembleia-geral do Grémio Nacional dos Editores e Livreiros, as

[...] causas da nossa decadência no mercado brasileiro são várias. À dispersão de esforços, ao mercantilismo excessivo, à exploração e à inacção de um comércio muitas vezes sem recursos e sem meios de acção [...] há a juntar dois outros de capital importância: o desenvolvimento editorial brasileiro e, especialmente, o custo das taxas postais arbitradas para o livro (DIÁRIO DE NOTÍCIAS, 1941, p.1).

Por seu turno, Lobo Vilela, diretor literário da Editorial Gleba, no princípio da década de 1940, em entrevista concedida a Irene Lisboa não evita o desabafo. "É constrangedor ver como o livro português está quase banido do Brasil, sobretudo o livro moderno, e como o livro brasileiro se tem espalhado em Portugal!” (LISBOA, 1944, p. 41). O conjunto de argumentos dos editores portugueses estabelece-se com base no reconhecimento da estagnação da edição nacional, ultrapassada pelo dinamismo e arrojo inovador que o sector experimentava além-Atlântico. Arménio Amado, editor conimbricense e sócio fundador da Coimbra Editora, afirma também em entrevista à escritora portuguesa: 
Já lá vai o tempo em que as nossas livrarias expediam tudo quanto tinham em armazém para o Brasil! Até os livros de verso sem possível consumo... E por lá se gastavam! Porém, hoje os processos de comerciar têm de ser outros. Há cinquenta anos invadíamos nós o mercado brasileiro com os nossos livros, hoje voltou-se o feitiço contra o feiticeiro [...]. Hoje as oficinas tipográficas brasileiras são notáveis. E notáveis as suas casas editoras! Este país está magnificamente apetrechado para nos bater e até nos esquecer: quanto à sua indústria, à expansão do livro, à selecção e tradução deste, etc. (LISBOA, 1944, p. 100).

Opinião semelhante é declarada à mesma autora por João António de Carvalho, livreiro moçambicano da Minerva Central, para quem “os editores brasileiros têm uma maneira tão larga de comerciar, e os livros que nos últimos tempos têm lançado no mercado são de tão boa factura mecânica e já tão interessante literariamente, que se não estranha que breve açambarquem os mercados da língua” (LISBOA, 1944, p. 250). Os diagnósticos tocam ainda na dimensão das editoras brasileiras, logo, na sua capacidade de suportarem o risco com recurso a montantes de capital muito mais amplos do que os possíveis às "pequenas iniciativas” nacionais. Ainda na primeira metade dos anos 1940, Manuel Rodrigues de Oliveira, editor das Edições Cosmos, considera com desassombro que a

[...] produção brasileira está hoje subordinada a grandes empresas, como todos sabem. O Brasil cria e traduz em grande escala, por conta própria. É ele que abastece as colónias portuguesas da América do Norte, não nós. [...] O nosso livro vive das pequenas iniciativas e não afinal da expansão que a própria língua lhe podia assegurar (LISBOA, 1944, p. 21).

Os ecos da mudança pressentida continuam a fazer-se ouvir no início da década seguinte. Os irmãos Lyon de Castro, Francisco e Adelino, fundadores em conjunto com Manuel Rodrigues de Oliveira das Publicações Europa-América em 1945, por exemplo, em lúcido e precoce editorial do seu jornal, interpretaram a dinâmica de transformação, aparentemente opaca para alguns. Com clareza, o texto de 1952 explica que

[...] convém pormos de parte, e definitivamente, a ideia de que o Brasil ainda é um vasto campo de operações coloniais para o livro português. [...] Criaram-se assim as condições necessárias para o Brasil pensar que chegou o momento de se inverterem os papéis e a sua produção editorial desempenhar no nosso país o papel que outrora as nossas edições representavam para o leitor brasileiro, sendo, portanto, necessário não esquecer a emancipação cultural do Brasil (CASTRO; CASTRO, 1952, p. 2). 
Apesar destas percepções começarem a ser manifestadas relativamente cedo (pelo menos no dealbar da década de 1940), só um pouco mais tarde é possível distinguir a emergência deste movimento de reconhecimento do surto do livro no Brasil na generalidade dos editores portugueses. Em grande medida motivados pelas dificuldades - anteriormente desconhecidas - na exportação de livros para o mercado brasileiro, mas também movidos por uma lenta tomada de consciência do desenvolvimento editorial do Brasil, os agentes do setor do livro em Portugal, só no término dos anos 1950, começam a construir uma imagem renovada do papel dos congêneres brasileiros, da sua produção editorial e das mutações nas apetências do seu público.

No esteio deste reconhecimento da existência de transformação no espaço editorial brasileiro, visto como mais legítimo e maduro, surge mais tarde uma série de sugestões de entendimento coletivo, de propostas de certames conjuntos de caráter institucional e de alvitres para centrais de distribuição da produção livreira de cada um dos países no outro. Face a dificuldades crescentes, os editores portugueses passavam a entrever o Brasil como oportunidade que merecia um novo tipo de relação, não somente já baseada de forma exclusiva na exploração - cada vez mais impossível - de um ente passivo e dependente, mas antes alicerçada na ideia de parceria e colaboração. Houve mesmo lugar a iniciativas de reaproximação como a realização, em 11 de outubro de 1966, da primeira Feira do Livro Brasileiro em Lisboa, simultânea (à hora) da primeira Feira do Livro Português no Rio de Janeiro. O seu caráter avulso e inconsequente não logrou, no entanto, qualquer eficácia. O mercado brasileiro como destino natural de escoamento para o livro português desaparecia, e essa realidade era finalmente incorporada pelo campo do livro em Portugal. Não sem hesitações e não sem que permanecesse nas concepções de vários agentes ligados ao livro, não necessariamente editores, um certo e, por vezes, deliberadamente mal disfarçado sentimento nostálgico. Não é de admirar que, ainda nos anos 1960, surgisse na imprensa uma profusão de artigos sobre o desaparecimento daquele que continuava ser encarado por muitos como o grande território de exportação ${ }^{3}$.

\section{A atuação dos agentes concretos: fora do eixo conflitual, o caso da editora Livros do Brasil}

Em todo o caso, salienta-se que nem todas as tentativas de contrainfluência portuguesa do processo de desenvolvimento editorial brasileiro se orientaram pelas propostas colaborativas como caminho exploratório para permanecer ou reentrar no mercado brasileiro do livro. Assiste-se, por exemplo, a algumas movimentações de descontentes com a situação que não deixaram de apelar mais ou menos diretamente para a intervenção do Estado - administrativa, política e até diplomática - em questões como a dos pagamentos “atrasados” (MEDEIROS, 2010). 
Influência e contra-influência na inversão do poder tipográfico entre Portugal e o Brasil. Narrativa e actividade nos editores portugueses

É evidente, portanto, que as representações que os agentes do livro, sobretudo os editores, iam construindo acerca do espaço tipográfico brasileiro e das transformações que este ia exibindo não constituíam um bloco homogêneo. Não se olhava de maneira uniforme a edição e a livraria brasileira. Apesar de emergirem discursos, predominantes e facilmente perceptíveis, sobre o mercado e a indústria brasileira do livro, os agentes do livro em Portugal não traçaram uma narrativa única e monolítica sobre esse mesmo mercado e essa mesma indústria. Os editores e livreiros portugueses foram, então, elaborando de modos variados os seus esquemas interpretativos do espaço brasileiro enquanto centro produtor e disseminador do livro. E esses posicionamentos discursivos diversificados foram alimentando formas também diversificadas de atuação editorial e livreira. Na década de 1960, por exemplo, verifica-se a tentativa de internacionalização da parte de algumas editoras portuguesas, procedendo a uma exploração do mercado brasileiro, que experimentava novo momento de transformação, mais visível no plano qualitativo do que no quantitativo, caracterizando-se essencialmente por um "reforço mútuo entre o público leitor e editores [...] que, para acompanhar esse público e vender seus livros, tinham que se aprimorar qualitativamente cada vez mais” (REIMÃO, 1996, p. 51-52). Dos projetos ensaiados, evidenciam-se o da Livraria Morais Editora (criada em 1922 por João de Araújo Moraes e comprada por António Alçada Baptista em 1958, o que consistiu num verdadeiro momento refundador), com a Editora Morais e o da Editorial Verbo (fundada por Fernando Guedes, Sebastião Alves e José Maria Alves em 1958), com a Editora Verbo. Estas experiências assumiram um caráter relativamente isolado e, sobretudo no caso da Editora Morais, não tiveram resultados de expansão comercial duradouros.

As alterações suscitadas na visão portuguesa do Brasil editorial produziram, assim, um leque de perspectivas, pluralidade essa que sobreveio num contexto de flutuação, frequentemente tensional, entre, por um lado, um conjunto de representações presas discursivamente a um tempo pretérito e dourado que chegava ao fim e, por outro, o aparecimento de práticas efetivas de colaboração e até de aproximação entre os mundos português e brasileiro do livro - práticas deixadas à ação individual de editores, dada a inação ou inépcia no lado português do Estado e do grêmio do setor. Entre esses atores individuais avulta, sem dúvida, citando apenas editores portugueses, o nome de António de Sousa Pinto, com os projetos da editora e livraria Livros de Portugal (situada no Brasil) e da editora Livros do Brasil (localizada em Portugal).

António de Sousa Pinto nasceu no Porto, em 1901, e passou a infância e a adolescência em Angola, indo viver para o Brasil, onde constitui no Rio de Janeiro, em finais da década de 1930, com Pedro de Andrade e Américo Fraga Lamares, a editora Livros de Portugal (também livraria, a funcionar a partir de 1941), dedicada à divulgação da literatura portuguesa. É nela que é publicada a 
importante coleção “Clássicos e Contemporâneos”, dirigida por Jaime Cortesão e ilustrada por Vieira da Silva, e na qual se editam nomes das letras portuguesas como Camões, Eça de Queiroz, José Rodrigues Miguéis, Fialho de Almeida, Gonçalves Crespo, saindo ainda antologias organizadas por Aquilino Ribeiro, Manuel Bandeira, Afrânio Peixoto, José Lins do Rego, Pedro Calmon. Regressando a Portugal, em 1944, Sousa Pinto logo empreende a consecução de nova editora nos mesmos moldes e com objetivo igual ao da sua congênere brasileira, que funda em Lisboa em 9 de junho desse ano, conjuntamente com Joaquim de Sousa Pinto. Em anúncio publicado em agosto de 1945, a jovem empresa apresenta-se como importadora e distribuidora do livro brasileiro, com representação exclusiva para Portugal e colônias de um conjunto de editoras brasileiras, e exportadora do livro português, para além de editora (GRÉMIO NACIONAL DOS EDITORES E LIVREIROS, n. 42, ago. 1945, p. 137). É nesta última componente que a Livros do Brasil se afirmará em breve trecho. Incapaz de cumprir as suas potencialidades e de assegurar a sua vocação divulgadora baseada apenas na vertente de importação, a Livros do Brasil procura, pouco depois de ter encetado atividade, a realização plena da sua existência: a edição de livros.

A Livros do Brasil não demorará muito tempo a tornar-se uma das maiores editoras portuguesas e uma das mais marcantes do século $\mathrm{XX},{ }^{4}$ contribuindo fortemente para a consolidação em Portugal do consumo do livro de bolso, com a coleção “Miniatura” e para a sedimentação dos livros policiais e de ficção científica, com as séries "Vampiro” e “Argonauta”, que durante décadas se constituíram com as referências dos respectivos gêneros. Tendo sido ainda uma chancela que apostou na difusão dos grandes nomes da literatura internacional de entre as duas guerras mundiais, com um acervo que é quase equivalente a um espólio do cânone literário ocidental da primeira metade do século XX, a Livros do Brasil destacou-se, sobretudo, pelo catálogo que deixou em termos de difusão das letras brasileiras. Sousa Pinto cria a série "Livros do Brasil”, homônima da editora e durante décadas a única - ainda nos dias de hoje indiscutivelmente a mais extensa e importante - no panorama nacional integralmente dedicada a escritores brasileiros, a maioria dos quais é introduzida em Portugal pela Livros do Brasil. Em Olhai os lírios do campo, de Erico Veríssimo, volume inaugural da coleção, o editor faz publicar uma nota prévia intitulada “Objectivo da ‘Colecção Livros do Brasil’”, dela constando o seguinte texto:

A firma Livros do Brasil, L.da, cuja acção editorial tem sido orientada de um modo especialmente fiel à sua designação - pela divulgação do livro brasileiro em Portugal - reconheceu, ao cabo de alguns anos de esforço, que a sua iniciativa era dificultada e prejudicada pelas sempre crescentes despesas de importação, extraordinariamente agravadas pela diferença cambial entre os dois países. O livro brasileiro, importado, torna-se hoje dificilmente acessível ao público português, dadas as sobrecargas que o oneram e que não encontram compensação no nosso 
nível de vida. Por outras palavras: é impraticável uma larga divulgação em Portugal de livros de autores brasileiros editados no país irmão em vista das inevitáveis diferenças de preços. [par.] Ora, a firma Livros do Brasil, L.da, impôsse, em primeiro lugar, uma missão de divulgação cultural. Entende que o livro não pode ser luxo de raros, mas sim matéria acessível a toda a gente. [par.] Perante este problema, uma questão resultou da experiência da sua actividade. Como tornar acessíveis ao público português as obras-primas da literatura brasileira, contemporânea ou não, que tanto enriquecem o património da língua portuguesa? [par.] A solução encontra-se, embora com sacrifício imediato, num acordo com as grandes editoras do Brasil. Mas, correspondendo, assim, ao seu plano inicial, de que não quer afastar-se, espera encontrar também compensação no acolhimento que o nosso público tem dado sempre às suas edições e que, com mais razão ainda, continuará a dar-lhe de futuro. [par.] Nessa conformidade, Livros do Brasil, L.da, inicia com o presente volume uma colecção das obras mais representativas da literatura brasileira contemporânea - romances, ensaios, novelas, crítica - na certeza de que, editando-as no nosso País, as irá revelando sucessivamente ao público português em condições mais acessíveis às suas possibilidades (EDITOR, s.d., p. 5).

Do seu fundo editorial, publicados entre meados da década de fundação, anos 1940, e meados da década de 1970, constam, entre outros, autores como Erico Veríssimo, Jorge Amado, Clarice Lispector, Joracy Camargo, José Lins do Rego, Carolina Nabuco, Caio de Freitas, Euclydes da Cunha, Cyro dos Anjos, José de Alencar, Fernando Sabino, Lygia Fagundes Teles, José Condé, Octávio de Faria, João Guimarães Rosa, Berenice Grieco, Ribeiro Couto, António Olavo Pereira, Herberto Sales, Odylo Costa Filho, Agrippino Grieco, Heitor Lyra, Otto Lara Resende, Gilberto Freyre, Paulo Cavalcanti, Rubem Braga, Jarbas Passarinho, Mário Palmério, José Cândido de Carvalho, Gastão de Holanda ou Viana Moog. A série impressionante de autores brasileiros é bem o sinal do projeto de divulgação editorial levado a cabo por Sousa Pinto, indiciando um espírito indesmentível de mediação e prescrição na edição (MEDEIROS, 2009), difundindo em terras portuguesas um conjunto de escritores e, por essa via, oferecendo-lhe eco e dimensão internacional no mundo de língua portuguesa, ao mesmo tempo que contribui para suscitar um mercado específico de consumo literário. Esta dimensão prescritiva é acrescida pela criação de um prêmio literário, o "Prémio José Lins do Rego”, que o editor português institui, em 1961, reforçando a sua intervenção consagradora. O prêmio, único em Portugal a ostentar o nome de um autor brasileiro, conheceu somente uma edição. Não obstante esse fato, a sua instituição traduz a vontade de intervenção editorial no mercado português valendo-se da ideia de divulgação do patrimônio literário do Brasil. 


\section{Comentário final}

Como breve conclusão, pode dizer-se que, na relação entre Portugal e Brasil no atinente ao mundo do livro, as alterações ocorridas na ligação comercial e simbólica entre os dois países terão dado origem a uma inversão de poder tipográfico - no que esta noção encerra em termos de influência e capacidade de expansão editorial num quadro complexo de circulação e de mútua ou múltipla apropriação do livro - que parece iniciar-se como processo a partir de meados dos anos 30, princípios dos anos 40 do século XX. O outrora espaço autorrepresentado como dominante, exibindo um campo do livro que atua no pressuposto de se conceber como claramente exportador face à dependência de um outro espaço, visto à luz de um resíduo colonial como mercado passivo e natural, é ultrapassado pelo antigo espaço encarado como dominado, cujo surto de desenvolvimento tipográfico subverteu uma ordem do livro em grande medida perspectivada pelo lado português como estabelecida de modo durável - num cenário, aliás, em que em ambas as margens do Atlântico, a presença e influência tipográfica foi plural, recebendo amplo contributo da edição francesa e dos seus editores (DOMINGOS, 2000; CURTO et al., 2007; BRAGANÇA; ABREU, 2010; ABREU, 2011; DEAECTO, 2011).

No decurso do processo em que se concretiza esta inversão são colocadas em jogo, lado a lado, estratégias de influência e de contrainfluência, num trajeto não-linear nem homogêneo, tanto nas circunstâncias em que teve lugar quanto nos agentes que lhe deram corpo. A tensão assim gerada não conheceu apenas um registro conflitual, mas correspondeu a caminhos variados em que as propostas de colaboração e o estabelecimento de pontes foram, por vezes, não apenas recursos retóricos, frutos de uma lenta aceitação pela generalidade das gentes do livro portuguesas de que a realidade havia mudado, ${ }^{5}$ mas também formas efetivas de atuação levadas a cabo mais por editores e livreiros individuais do que por iniciativas coletivas e institucionais, sobressaindo, no caso português, o exemplo de António Sousa Pinto e da editora Livros do Brasil.

\section{Notas}

\footnotetext{
${ }^{1}$ Traços salientes da cultura nacional consagrados tipograficamente em países como Portugal e Brasil foram-no, a partir da intervenção editorial e livreira ativa de estrangeiros, essencialmente franceses, embora para o caso brasileiro se tenham registrado intervenções de editores de outras proveniências nacionais (LOPES, 2001; ABREU, 2011).

${ }^{2}$ Confira-se, a título de ilustração, a entrevista concedida por Joaquim de Oliveira Antunes, livreiro brasileiro, ao periódico Vamos Ler (cit. em GRÉMIO NACIONAL DOS EDITORES E LIVREIROS, n. 32, out. 1944, p. 13).

${ }^{3}$ Uma incursão panorâmica na imprensa periódica portuguesa permite concluir que ainda em finais dos anos 1960 , inícios dos anos 1970, a narrativa angustiada do declínio em terras brasileiras do livro editado em Portugal estava longe de desaparecer. Num registro que oscila entre sentimentos mais pessimistas e tonalidades mais otimistas, o tópico surge, por exemplo, nas páginas do Diário de Lisboa (8 de mar. 1968, 11 de mar. 1969, etc.), do Diário Popular (4 de fev. 1965, 27 de fev. 1969, 4 de fev. 1971, etc.), d’A Capital (22 de mar. 1968, 27 de jul. 1968, etc.), do Diário de Notícias
} 
(5 de ago. 1967), d'O Primeiro de Janeiro (2 de nov. 1967), da Vida Mundial (15 de dez. 1967), entre outras publicações.

${ }_{5}^{4}$ Ao fim de trinta anos de atividade, a Livros do Brasil contava com um catálogo de dois mil títulos.

${ }^{5}$ Embora, como se viu, o reconhecimento - até com desassombro e inclusive de forma elogiosa - do avanço da indústria do livro no Brasil esteja presente no discurso de alguns agentes do campo editorial e livreiro português logo no início da década de 1940.

\section{Referências:}

ABREU, M. Duzentos anos: os primeiros livros brasileiros. In: BRAGANÇA, A., ABREU, M. Impresso no Brasil: dois séculos de livros brasileiros. São Paulo: Unesp, 2010, p. 41-65.

ABREU, M. A circulação transatlântica dos impressos. A globalização da cultura no século XIX. Livro. Revista do núcleo de estudos do livro e da edição, n. 1, p. 115-127, maio 2011.

ANÓNIMO. O desacordo ortográfico luso-brasileiro. Língua Portuguesa, v. XX, p. 305-317, 1955.

BARBIER, F. La librairie allemande comme modèle? In: MICHON, J., MOLLIER, J.-Y. Les mutations du livre et de l'édition dans le monde du XVIIIe siècle à l'an 2000. Saint-Nicolas e Paris: Presses de l’Université Laval e L’Harmattan, 2001, p. 31-45.

BRAGANÇA, A. A constituição do campo interdisciplinar de estudos do livro e da história editorial no Brasil (1900-2000). In: BRAGANÇA, A., MOREIRA, S. Comunicação, acontecimento e memória. São Paulo: Intercom, 2005, p. 79-94.

BRAGANÇA, A. António Isidoro da Fonseca e frei José Mariano da Conceição Veloso: precursores. In: BRAGANÇA, A.; ABREU, M. Impresso no Brasil: dois séculos de livros brasileiros. São Paulo: Unesp, 2010, p. 25-39.

BRAGANÇA, A.; ABREU, M. (Orgs.). Impresso no Brasil: dois séculos de livros brasileiros. São Paulo: Unesp, 2010.

CÂMARA BRASILEIRA DO LIVRO. Primeiro congresso de editôres e livreiros do Brasil. São Paulo: Saraiva, 1950.

CASTRO, A. L. De; CASTRO, F. L. de. Editorial. Ler, Jornal de Letras, Artes e Ciências, n. 3, p. 2, jun. 1952.

CERTEAU, M. L'invention du quotidien. [S.l.]: Gallimard, 1990, v. I, Arts de faire [1.a ed. estabelecida por Luce Giard].

CHARTIER, R. Culture écrite et société. Paris: Albin Michel, 1996.

CHARTIER, R. A ordem dos livros. Lisboa: Vega, 1997.

CHARTIER, R. Cultura escrita, literatura e história. Conversas de Roger Chartier com Carlos Aguirre Anaya, Jesús Anaya Rosique, Daniel Goldin e Antonio Saborit. Porto Alegre: Artmed, 2001. 
CURTO, D. R.; DOMINGOS, M. D.; FIGUEIREDO, D.; GONÇALVES, P. As gentes do livro: Lisboa, século XVIII. Lisboa: Biblioteca Nacional, 2007.

DEAECTO, M. M. O império dos livros. Instituições e práticas de leitura na São Paulo oitocentista. São Paulo: Edusp e Fapesp, 2011.

DIÁRIO DE NOTÍCIAS. O S.O.S. do livro português. Diário de Notícias, p. 1, 15 de fev. 1941.

DOMINGOS, M. D. Livreiros de setecentos. Lisboa: Biblioteca Nacional, 2000.

EDITOR. Objectivo da 'Colecção Livros do Brasil'. In: VERÍSSIMO, E. Olhai os lírios do campo. 3.a ed. Lisboa: Livros do Brasil, s.d.

HALLEWELL, L. O livro no Brasil: sua história. São Paulo: T. A. Queiroz e Edusp, 1985.

LEÃO, F. da C. Sobre a expansão do livro português, nas províncias ultramarinas. Boletim Geral do Ultramar, n. 332, p. 49-70, fev. 1953.

LISBOA, I. Inquérito ao livro em Portugal. Lisboa: Seara Nova, 1944. v. I, Editores e livreiros.

GRÉMIO NACIONAL DOS EDITORES E LIVREIROS. Livros de Portugal. [boletim oficial do grémio] Lisboa: Grémio Nacional dos Editores e Livreiros, 1940 a 1947, 1952 a 1957, 1959 a 1971.

LOPES, C. N. Édition et colonisation: le marché éditorial entre le Brésil et le Portugal. In: MICHON, J., MOLLIER, J.-Y. Les mutations du livre et de l'édition dans le monde du XVIIIe siècle à l'an 2000. Saint-Nicolas e Paris: Presses de l’Université Laval e L'Harmattan, 2001, p. 360-371.

MEDEIROS, N. Editores e livreiros: que papéis de mediação para o livro? In: CURTO, D. R. Estudos de sociologia da leitura em Portugal no século XX. Lisboa: Fundação Calouste Gulbenkian, 2006. p. 343-385.

MEDEIROS, N. Acções prescritivas e estratégicas: a edição como espaço social. Revista Crítica de Ciências Sociais, n. 85, p. 131-146, 2009.

MEDEIROS, N. Edição e editores: o mundo do livro em Portugal, 1940-1970. Lisboa: Imprensa de Ciências Sociais, 2010.

MOLLIER, J.-Y. La construction du système éditorial français et son expansion dans le monde du XVIII ${ }^{\mathrm{e}}$ au XX $\mathrm{X}^{\mathrm{e}}$ siècle. In: MICHON, J.; MOLLIER, J.-Y. Les mutations du livre et de l'édition dans le monde du XVIIIe siècle à l'an 2000. Saint-Nicolas e Paris: Presses de l'Université Laval e L'Harmattan, 2001, p. 47-72.

MOREIRA, M. A nacionalização das letras da América portuguesa durante o romantismo. In: BRAGANÇA, A.; ABREU, M. Impresso no Brasil: dois séculos de livros brasileiros. São Paulo: Unesp, 2010. p. 519-533.

REIMÃO, S. Mercado editorial brasileiro, 1960-1990. São Paulo: Com-Arte e Fapesp, 1996. 
Influência e contra-influência na inversão do poder tipográfico entre Portugal e o Brasil. Narrativa e actividade nos editores portugueses

SORÁ, G. La maison et l'entreprise. José Olympio et l'évolution de l'édition brésilienne. Actes de la Recherche en Sciences Sociales, n. 126-127, p. 90-101, mar. 1999.

Recebido em 31/08/2011

Aprovado em 26/09/2011. 